\title{
Bariatric Surgery can Lead to Net Cost Savings to Health Care Systems: Results from a Comprehensive European Decision Analytic Model
}

\author{
Oleg Borisenko • Daniel Adam • Peter Funch-Jensen • \\ Ahmed R. Ahmed • Rongrong Zhang • Zeynep Colpan • \\ Jan Hedenbro
}

Published online: 2 February 2015

(C) The Author(s) 2015. This article is published with open access at Springerlink.com

\begin{abstract}
Background The objective of the present study was to evaluate the cost-utility of bariatric surgery in a lifetime horizon from a Swedish health care payer perspective.

Methods A decision analytic model using the Markov process was developed covering cardiovascular diseases, type 2 diabetes, and surgical complications. Clinical effectiveness and safety were based on the literature and data from the Scandinavian Obesity Surgery Registry. Gastric bypass, sleeve gastrectomy, and gastric banding were included in the analysis. Cost data were obtained from Swedish sources.
\end{abstract}

Electronic supplementary material The online version of this article (doi:10.1007/s11695-014-1567-5) contains supplementary material, which is available to authorized users.

O. Borisenko $(\bowtie) \cdot$ D. Adam $\cdot$ R. Zhang $\cdot$ Z. Colpan Synergus AB, Svardvagen 19, 18233 Danderyd, Sweden

e-mail: oleg.borisenko@synergus.com

D. Adam

e-mail: daniel.adam.blanco@gmail.com

R. Zhang

e-mail: rongrong.zhang@synergus.com

Z. Colpan

e-mail: colpan.zeynep@gmail.com

P. Funch-Jensen

Aarhus University, and Aleris Hamlet Hospital Aarhus,

Aarhus, Denmark

e-mail: funchjensen@gmail.com

\author{
A. R. Ahmed \\ Imperial College London, London, UK \\ e-mail: Ahmed.Ahmed@imperial.nhs.uk \\ J. Hedenbro \\ Aleris Obesity \& Lund University, Lund, Sweden \\ e-mail: jan.hedenbro@med.lu.se
}

Results Bariatric surgery was cost saving in comparison with conservative management. It also led to a substantial reduction in lifetime risk of events: from a $16 \%$ reduction in the risk of transient ischaemic attacks to a $62 \%$ reduction in the incidence of type 2 diabetes. Over a lifetime, surgery led to savings of $€ 8408$ and generated an additional 0.8 years of life and 4.1 quality-adjusted life years (QALYs) per patient, which translates into gains of 32,390 quality-adjusted person-years and savings of $€ 66$ million for the cohort, operated in 2012. Analysis of the consequences of a 3-year delay in surgery provision showed that the overall lifetime cost of treatment may be increased in patients with diabetes or a body mass index $>40 \mathrm{~kg} / \mathrm{m}^{2}$. Delays in surgery may also lead to a loss of clinical benefits: up to 0.6 life years and 1.2 QALYs per patient over a lifetime.

Conclusion Bariatric surgery, over a lifetime horizon, may lead to significant cost savings to health care systems in addition to the known clinical benefits.

Keywords Bariatric surgery - Cost-utility analysis · Cost-effectiveness analysis - Health economics - Cost . Sweden

\section{Introduction/Purpose}

Obesity is a global epidemic. Considering the limited effectiveness of conservative weight loss methods in severely obese patients [1-3], bariatric surgery is the only available treatment option. Because of the increased financial pressure, there is an ongoing need to inform decision-makers and surgeons about the economic consequences of bariatric surgery to health care systems in European countries. The objective of the present study was to develop a comprehensive decision analytic model for bariatric surgery to support decision- 
making for priority setting for the treatment of obesity in European countries.

\section{Patient Materials and Methods}

Decision analytic modeling was employed to evaluate the cost-effectiveness of bariatric surgery. A Markov process [4] was developed covering surgery and post-surgery, postsurgery complications, type 2 diabetes, angina pectoris, myocardial infarction, stroke, transient ischaemic attack, heart failure, and peripheral arterial disease states. In the Markov model during each cycle, which is equal to 1 month, a patient may progress to another health state (e.g., healthy individual in post-surgery state may experience stroke) or remain in the previous state. Each state is associated with specific cost and utility (based on health-related quality of life). The flow of patients in the surgical arm is presented in Fig. 1. The flow of patients in the optimal medical management arm is the same with the exception of absence of initial surgery, conversion surgery, and surgical complications states. Costeffectiveness was evaluated over a lifetime perspective. Additional information on methods is provided in section $\mathrm{S} 1$ of Supplemental Material.
Input Data

\section{Clinical Effectiveness and Safety Data}

The model operates by predicting the risk of cardiovascular events, type 2 diabetes, and complications of surgery. The risk of cardiovascular events is predicted by the patient's characteristics (age, gender, level of systolic blood pressure (SBP), level of body mass index (BMI), presence of diabetes, and smoking status), which can increase or decrease the risk of events [5-9]. Short-term safety was informed by the Michigan Bariatric Surgery Registry data [10, 11], and data for long-term safety of surgery were based on information from the Scandinavian Obesity Surgery Registry (SOREG) [12]. Cholecystectomy, abdominal hernia repair, leakage and abscess, gastric stricture, gastric ulcer, skin surgery, and conversion surgery were considered.

The premise of the analysis is that the risk of cardiovascular events and diabetes depends on multiple risk factors and, by modifying some of these factors (BMI, SBP, presence of diabetes), the overall risk can be modified. By modeling the risk in the surgical arm and in a hypothetical cohort of nonoperated patients, it is then possible to quantify the impact of surgery on the rate of long-term adverse events.

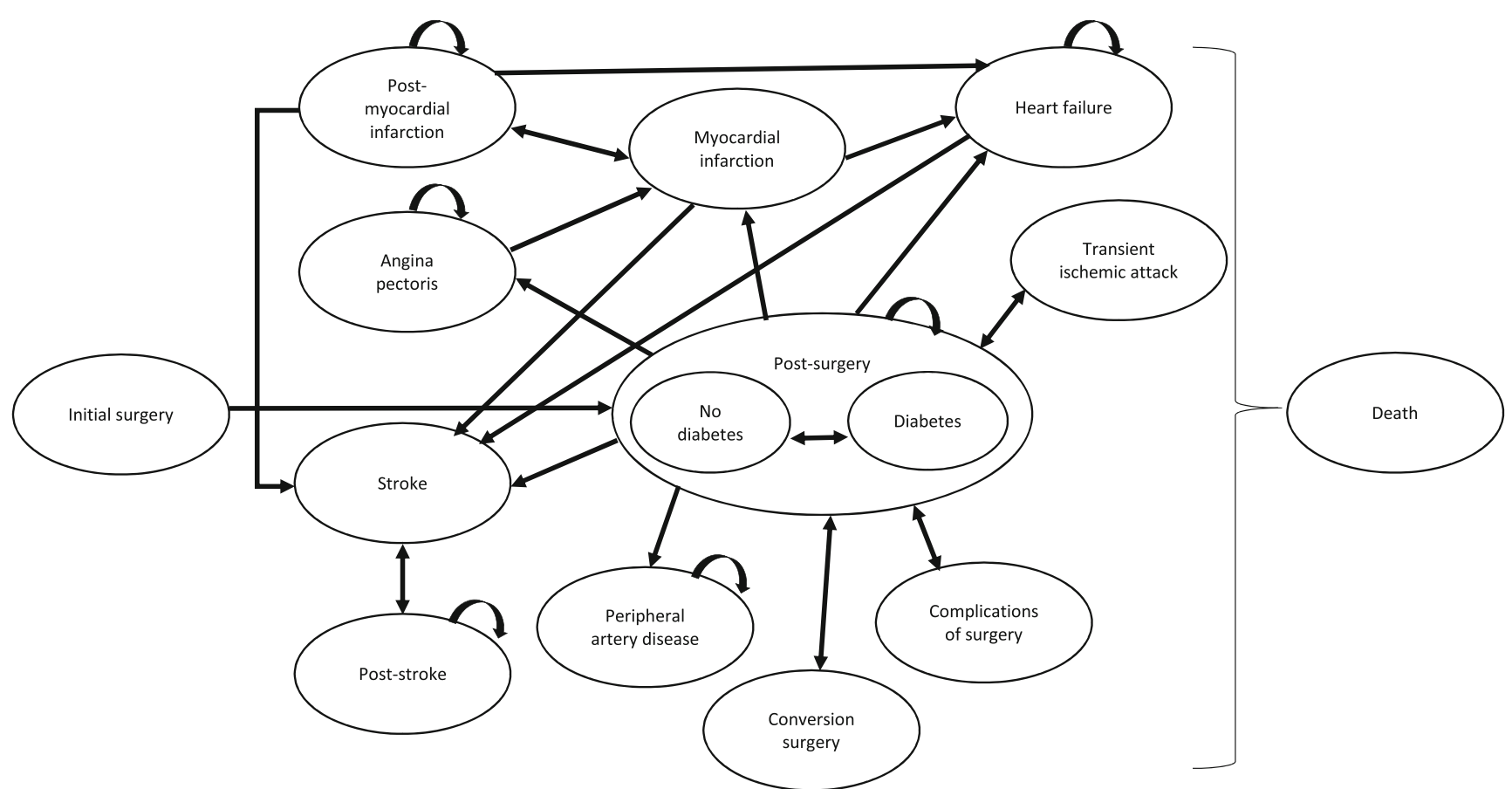

Fig. 1 Structure of the Markov model. The figure presents the structure of the Markov model. Patients in the surgical arm enter the model through the "Initial surgery" state and, in the next cycle, move to either "Diabetes post-surgery" or "No Diabetes post-surgery" state depending on the presence or absence of diabetes at the start of the analysis. Patients may recover from diabetes or experience diabetes. From any of the postsurgery state, patients can experience angina pectoris, myocardial infarction, heart failure, transient ischaemic attack, stroke, peripheral arterial disease, complications of surgery, or undergo conversion surgery if weight loss was not achieved. Patients can also move from one negative health state to another (i.e., experience a stroke after being in a heart failure state). Patients may also die from any state. Patients in the medical management arm enter the model either through "Diabetes" or "No diabetes" state. They can experience the same negative events except for complications of surgery or conversion surgery 
Three of the most common surgical approaches were included into the model: gastric bypass (GBP), sleeve gastrectomy (SG), and adjustable gastric banding (GB). Although GB has a very limited utilization is Sweden, it was included for comparative purposes. The relationship between the different surgical methods and the BMI level was derived from SOREG 2011 data for base-case analysis [12]. Using the latest follow-up observation available (2 years), the impact on the BMI was extrapolated using data on BMI change from the Swedish Obese Subjects (SOS) study [13]. After 15 years, the BMI level was assumed stable for the rest of the patient's life. Changes in BMI in the optimal medical management arm were derived from changes of BMI in the control arm of the SOS study [13]. The major clinical inputs are presented in Table 1 (additional inputs are presented in Table S1).

\section{Resource Utilization and Cost Data}

Cost data were determined using Swedish sources. The basecase analysis included only direct medical costs.

The number of surgical procedures as well as the rate of use of the different surgical methods (GBP-98 \%, SG-1.6\%, GB- $0.4 \%$ ) were obtained from SOREG [12].

The costs of complications of obesity were obtained from the literature [15-17, 19-21]. The major cost data are presented in Table 1 (additional information in Table S1). For the scenario analysis, the indirect cost of end-stage events was added to the analysis. The cost data are presented in 2012 euros. The inflation adjustment of values in Swedish krona was initially performed using the Swedish consumer price index [22], and values were then, as recommended in the literature [23], converted into euro currency $(1 \mathrm{SEK}=0.089$ euro) using purchase power parities [24].

\section{Utility Data}

Health-related quality of life (HRQoL) was expressed on the basis of the generic HRQoL instrument, EuroQol-5D (EQ$5 \mathrm{D}$ ), and was dependent on the BMI level and the presence of diabetes [25]. The impact of complications of obesity on quality of life was based on the literature [26]. Utility data are presented in Table S1.

\section{Cohort Description}

Two types of cohorts were evaluated in the model. First, analysis in the so-called multiple cohorts was performed based on a cohort of real candidates for surgery in Sweden. Characteristics of patients for analysis were obtained from SOREG [12], the SOS study [9], and the OECD data [14] (Table 1). Second, the cost-effectiveness of bariatric surgery was estimated in 16 cohorts of 41 -year-old non-smoking males and females with different BMI levels: 30-34 (moderate), 35-39 (severe), 40-50 (morbid), and $>50 \mathrm{~kg} / \mathrm{m}^{2}$ (super obese). Further sub-classification was made for the presence or absence of type 2 diabetes.

\section{Analysis}

The incremental cost-effectiveness ratio (ICER) was calculated by comparing the difference in the average total costs with the difference in the average quality-adjusted life years (QALYs) among the study's arms. All costs and outcomes beyond the first year were discounted at the rate of $3.0 \%$ annually according to Swedish recommendations [27]. The intervention was considered cost-effective if the ICER was below $€ 35,526$ per QALY [28-30]. It means that to be considered cost-effective in Sweden, medical technology needs to lead to additional cost of no more than $€ 35,526$ for one extra year of life of full health (QALY).

In addition to the standard evaluation of cost-effectiveness between two treatment options, an analysis was performed on the impact of waiting lists (delay in surgery provision) on the clinical and economic outcomes. The patients were initially included in the optimal medical management arm and then moved to the surgical arm after 3 years. The results were compared with those of patients who underwent immediate surgery.

The model was constructed using Microsoft Excel 2010 (Microsoft Corp., Redmond, WA, USA) and was extensively validated with results provided in Supplementary material.

\section{Sensitivity and Scenario Analysis}

A one-way deterministic sensitivity analysis was performed to assess the impact of varying the model parameters while holding other variables fixed at base-case values. In addition to a one-way sensitivity analysis, 11 additional scenarios were tested (Section S3). To address sampling uncertainty, a probabilistic sensitivity analysis (PSA) was performed using 5000 Monte Carlo simulations. In PSA, specific distribution (i.e., normal, log-normal, beta, gamma, and uniform) is determined for every parameter; during 5000 runs (simulations) each parameter varies randomly within a pre-specified distribution. The outcomes of interest (cost, life years gained, and QALYs gained) are averaged across 5000 runs.

\section{Results}

Model Validation

The external validation showed that the model predicts the majority of clinical events (cardiovascular mortality, stroke, 
Table 1 Major clinical, cost, and utility inputs

\begin{tabular}{|c|c|c|c|c|}
\hline Parameter & Value & Range & $\begin{array}{l}\text { Distribution for probabilistic } \\
\text { sensitivity analysis }\end{array}$ & Source \\
\hline \multicolumn{5}{|l|}{ Patient baseline characteristic } \\
\hline Age, years & 41 & $25-65$ & Normal $(\mathrm{SD}=5)$ & \multirow[t]{4}{*}{ SOREG 2011 [12] } \\
\hline Gender, males $(\%)$ & 24 & NA & $\operatorname{Beta}(\alpha=1760 ; \beta=5874)$ & \\
\hline Body mass index, $\mathrm{kg} / \mathrm{m} 2$ & 42.8 & $30-60$ & Normal $(\mathrm{SE}=5.8)$ & \\
\hline Diabetes mellitus, (\%) & 18.39 & NA & $\operatorname{Beta}(\alpha=1404 ; \beta=6230)$ & \\
\hline Systolic blood pressure, $\mathrm{mmHg}$ & 140.1 & $125-200$ & Gamma $(\alpha=55.53 ; \lambda=2.52)$ & Sjostrom 2004 [9] \\
\hline Smoking, (\%) & 14.3 & NA & Beta $(\alpha=1128 ; \beta=6770)$ & OECD fact book [14] \\
\hline \multicolumn{5}{|c|}{ Absolute BMI reduction, reported in the Scandinavian Obesity Surgery Registry } \\
\hline GBP, 1-year, males & 12.7 & $8.7-37.7$ & Normal $(\mathrm{SD}=2.2)$ & \multirow[t]{12}{*}{ SOREG 2011 [12] } \\
\hline GBP, 2-year, males & 12.6 & $8.6-37.4$ & Normal $(\mathrm{SD}=2.2)$ & \\
\hline SG, 1-year, males & 9.7 & $5.9-25.5$ & Normal $(\mathrm{SD}=1.7)$ & \\
\hline SG, 2-year, males & 9.4 & $5.7-24.7$ & Normal $(\mathrm{SD}=1.6)$ & \\
\hline GB, 1-year, males & 5.6 & $3.9-16.9$ & Normal $(\mathrm{SD}=1.0)$ & \\
\hline GB, 2-year, males & 6.9 & $4.8-20.9$ & Normal $(\mathrm{SD}=1.2)$ & \\
\hline GBP, 1-year, females & 13.5 & $9.5-41.1$ & Normal $(\mathrm{SD}=2.4)$ & \\
\hline GBP, 2-year, females & 13.5 & $9.5-41.2$ & Normal $(\mathrm{SD}=2.4)$ & \\
\hline SG, 1-year, females & 12.5 & $7.5-32.8$ & Normal $(\mathrm{SD}=2.2)$ & \\
\hline SG, 2-year, females & 14.7 & $8.9-38.0$ & Normal $(\mathrm{SD}=2.6)$ & \\
\hline GB, 1-year females & 5.5 & $3.9-17.0$ & Normal $(\mathrm{SD}=0.9)$ & \\
\hline GB, 2-year, females & 5.1 & $3.6-15.7$ & Normal $(\mathrm{SD}=0.9)$ & \\
\hline \multicolumn{5}{|l|}{ Other clinical inputs } \\
\hline $\begin{array}{l}\text { Proportion of patients with remission of } \\
\text { diabetes at } 2 \text { years, surgical arm }\end{array}$ & 0.72 & $0.67-0.77$ & $\operatorname{Beta}(\alpha=246 ; \beta=95)$ & \multirow[t]{4}{*}{ Sjostrom 2004 [9] } \\
\hline $\begin{array}{l}\text { Proportion of patients with remission of } \\
\text { diabetes at } 2 \text { years, OMM arm }\end{array}$ & 0.21 & $0.15-0.27$ & $\operatorname{Beta}(\alpha=52 ; \beta=196)$ & \\
\hline $\begin{array}{l}\text { Proportion of patients with remission of } \\
\text { diabetes at } 10 \text { years, surgical arm }\end{array}$ & 0.36 & $0.25-0.50$ & $\operatorname{Beta}(\alpha=42 ; \beta=76)$ & \\
\hline $\begin{array}{l}\text { Proportion of patients with remission of } \\
\text { diabetes at } 10 \text { years, OMM arm }\end{array}$ & 0.13 & $0.07-0.22$ & $\operatorname{Beta}(\alpha=11 ; \beta=73)$ & \\
\hline \multicolumn{5}{|l|}{ Cost inputs, $€$} \\
\hline Cost of bariatric surgery without complications & 4915 & $3932-5898$ & NA & NordDRG tariff L08E \\
\hline Cost of bariatric surgery with complications & 5766 & $4613-6919$ & NA & NordDRG tariff L08C \\
\hline Annual cost of diabetes type 2 & 2713 & $1356-5426$ & Gamma $(\alpha=100 ; \lambda=305)$ & Henriksson 2000 [15] \\
\hline $\begin{array}{l}\text { Annual cost of acute stroke } \\
\text { Annual cost of post-stroke } 1 \text { year }\end{array}$ & $\begin{array}{l}7532 \\
7779\end{array}$ & $\begin{array}{l}3766-15,063 \\
3889-15,558\end{array}$ & $\begin{array}{l}\text { Gamma }(\alpha=100 ; \lambda=848) \\
\operatorname{Gamma}(\alpha=100 ; \lambda=875)\end{array}$ & \multirow[t]{2}{*}{ Ghatnekar 2004 [16] } \\
\hline Annual cost of post-stroke 2 year and onwards & 5784 & $2892-11,569$ & Gamma $(\alpha=100 ; \lambda=651)$ & \\
\hline Cost of transient ischemic attack & 1928 & $1542-1851$ & NA & NordDRG DRG tariff A47N \\
\hline Cost of acute myocardial infarction & 4592 & $2296-9183$ & Gamma $(\alpha=100 ; \lambda=516)$ & Henriksson 2011 [17] \\
\hline Annual cost of post-MI state & 3590 & $1795-7181$ & Gamma $(\alpha=100 ; \lambda=404)$ & Wilhelmsen 2010 [18] \\
\hline Annual cost of heart failure & 3895 & $1947-7790$ & Gamma $(\alpha=100 ; \lambda=438)$ & Agvall 2005 [19] \\
\hline Annual cost of peripheral artery disease & 4013 & $2006-8026$ & Gamma $(\alpha=100 ; \lambda=451)$ & Levy 2003 [20] \\
\hline Annual cost of angina pectoris & 4055 & $2027-8109$ & Gamma $(\alpha=100 ; \lambda=456)$ & Andersson 1995 [21] \\
\hline
\end{tabular}

$G B$ gastric banding, $G B P$ gastric bypass, $M I$ myocardial infarction, $O M M$ optimal medical management, $S G$ sleeve gastrectomy

health failure, angina, peripheral arterial disease, incidence and remission of diabetes) with a high degree of precision, although there was a tendency to overestimate all-cause mortality and combined (fatal and non-fatal) myocardial infarction. Details of the validation and evaluation of the model's performance are presented in Section S2.

\section{Base-Case Results in Multiple Cohorts Extrapolated from SOS and SOREG}

In the base-case analysis, bariatric surgery was cost saving in comparison with conservative management. In the simulation, surgery led to substantial reduction in the lifetime risk of 
Table 2 Number of events and relative risks over lifetime

\begin{tabular}{|c|c|c|c|c|c|c|c|c|c|}
\hline & Angina & MI total non-fatal & Fatal MI & Stroke total non-fatal & Fatal stroke & TIA & $\mathrm{HF}$ & PAD & Diabetes \\
\hline Absolute risk in surgical arm & $11 \%$ & $22 \%$ & $2 \%$ & $18 \%$ & $3 \%$ & $2 \%$ & $15 \%$ & $10 \%$ & $14 \%$ \\
\hline Absolute risk in OMM arm & $13 \%$ & $28 \%$ & $3 \%$ & $23 \%$ & $4 \%$ & $2 \%$ & $19 \%$ & $11 \%$ & $36 \%$ \\
\hline Relative risk & 0.82 & 0.80 & 0.70 & 0.79 & 0.78 & 0.84 & 0.84 & 0.84 & 0.38 \\
\hline
\end{tabular}

$H F$ heart failure, $M I$ myocardial infarction, $O M M$ optimal medical management, $P A D$ peripheral artery disease, $T I A$ transient ischemic attack

negative events (Table 2), from a $16 \%$ reduction in the risk of transient ischaemic attack to a $62 \%$ reduction in the incidence of type 2 diabetes. Over the lifetime of the cohort, surgery led to savings of $€ 8408$ and generated an additional 0.8 years of life or 4.1 QALYs per patient (Table 3). In Swedish settings, bariatric surgery becomes cost-effective (i.e., even though surgery may have higher cost, it leads to more benefits, and cost/ effect ratio is thus below accepted willingness-to-pay threshold in Sweden) after 2 years (ICER €26,985/QALY) and cost saving (i.e., surgery leads to more benefits at lower cost) after 17 years (Figure S5).

\section{Results in Specific Cohorts of Patients}

Analysis in specific cohorts revealed that bariatric surgery is cost saving in all of the four pre-specified diabetic cohorts (moderately, severely, morbidly, and super obese) in both male and female patients. In the non-diabetic cohorts, surgery was cost saving in all cohorts except for moderately obese male (ICER €459/QALYs) and female (ICER €51/QALYs) patients. In these two cohorts, surgery remained very costeffective (well below the willingness-to-pay threshold of $€ 35,526 /$ QALYs). Detailed results are provided in Tables S9-12. The degree of clinical benefits for the male and female cohorts is outlined in Fig. S6A-B.

Impact of Waiting Lists on the Clinical and Economic Outcomes of Bariatric Surgery

The analysis of the consequences of a 3-year delay in providing surgery showed that the overall lifetime cost in the surgical arm may be slightly reduced in non-diabetic patients with moderate and severe obesity $\left(\mathrm{BMI}<40 \mathrm{~kg} / \mathrm{m}^{2}\right)$, but the cost was increased in non-diabetic patients with morbid or super obesity and diabetic patients (increase from $€ 23$ to $€ 2803$ ) (Table 4, additional data in Table S13). Time delay in surgery led to significant losses of clinical benefits (in the range of 0 and 0.6 for life years and 0.2 and 1.2 for QALYs). Losses of clinical benefits are higher in males and diabetic patients.

\section{Sensitivity Analyses}

Deterministic one-way sensitivity analysis showed that four parameters can affect the cost saving effect of surgery (i.e., surgery becomes cost-effective): (1) the magnitude of the effect of surgery, (2) start age (better to operate patients when they are younger), (3) BMI (better to operate patients when BMI is lower), and (4) inclusion of an annual visit to a surgeon during the follow-up program from year three and onwards. Change of cost variables with $50 \%$ variations did not influence the cost saving effect of surgery. The most sensitive parameter from cost variables was the annual cost of type 2 diabetes.

The probabilistic sensitivity analysis demonstrated that bariatric surgery produces clinical benefits (additional QALYs) in all patients and has a cost saving effect in $99.1 \%$ of cases while, in the remaining $0.9 \%$, it is cost-effective (Fig. 2).

Additional 11 scenario analyses showed that uncertainty around the model inputs and structure did not affect the main results significantly (Section S4).

\section{Discussion}

The present study examines economic consequences of bariatric surgery in patients with severe obesity. As health care systems are operating under significant resource constraints, it

Table 3 Results of cost-effectiveness analysis

\begin{tabular}{llllllll}
\hline & Cost, $€$ & $\Delta$ cost, $€$ & LYG, years & $\Delta$ LYG & QALYs gained & $\Delta$ QALYs & ICER, €/QALY \\
\hline OMM arm & 34,665 & - & 21.4 & - & 9.4 & - & - \\
Surgical arm & 26,258 & -8408 & 22.2 & 0.8 & 13.5 & 4.1 & Dominates \\
\hline
\end{tabular}

Table presents results of cost-effectiveness analysis. Results demonstrate that surgery leads to lower cost and higher health gains compared with nonsurgical management, so surgery dominates over conservative management

ICER incremental cost-effectiveness ratio, $L Y G$ life years gained, OMM optimal medical management, $Q A L Y s$ quality-adjusted life years 
Table 4 Impact of 3-year delay in surgery provision on total cost of treatment, life years, and QALYs gained in different cohorts of patients

\begin{tabular}{|c|c|c|c|c|c|c|c|c|}
\hline \multirow[t]{2}{*}{ Population } & \multicolumn{2}{|c|}{ Moderately obese } & \multicolumn{2}{|c|}{ Severely obese } & \multicolumn{2}{|c|}{ Morbidly obese } & \multicolumn{2}{|c|}{ Super obese } \\
\hline & Males & Females & Males & Females & Males & Females & Males & Females \\
\hline \multicolumn{9}{|c|}{ Difference in total cost, $€$} \\
\hline Non-diabetic & -437 & -448 & -439 & -467 & 26 & -6 & 196 & 170 \\
\hline Diabetic & 2145 & 2708 & 2062 & 2625 & 2299 & 2803 & 2066 & 2551 \\
\hline \multicolumn{9}{|c|}{ Difference in life years gained } \\
\hline Non-diabetic & -0.1 & 0 & -0.2 & -0.1 & -0.2 & -0.1 & -0.2 & -0.1 \\
\hline Diabetic & -0.6 & -0.1 & -0.6 & 0 & -0.6 & 0 & -0.6 & -0.1 \\
\hline \multicolumn{9}{|c|}{ Difference in quality-adjusted life years gained } \\
\hline Non-diabetic & -0.3 & -0.2 & -0.3 & -0.3 & -0.6 & -0.5 & -0.8 & -0.7 \\
\hline Diabetic & -0.7 & -0.4 & -0.7 & -0.4 & -1 & -0.6 & -1.2 & -0.8 \\
\hline
\end{tabular}

Table presents modeled difference in cost and clinical outcomes between delayed and immediate surgery. Negative cost value indicates that delayed surgery leads to reduction of cost compared with immediate surgery. Positive cost value indicates that delayed surgery leads to increased cost compared with immediate surgery. Negative value of life years or QALYs gained indicates that delayed surgery leads to reduction of health benefits. For example, in moderately obese diabetic males, delayed surgery will lead to increase of cost of $€ 2145$ and loss of 0.6 life years or 0.7 QALYs

is important to ensure that health interventions are either aiming to reduce the cost of care or provide good value (clinical benefits) for the money spent (i.e., technologies are cost-effective). Like all other health interventions, bariatric surgery can be evaluated from an economic perspective to support decision-making about the appropriateness of funds allocation for this service.

In the present analysis, a decision analytic technique with Markov modeling was used to evaluate the long-term economic impact of surgery in the context of the Swedish health care system. Decision analytic modeling is a well-established approach in health economics $[4,23,31]$ and is recognized by health technology assessment bodies around the world [32-34] and is included into the standard procedures for the assessment of cost-effectiveness of technologies over a long time horizon. Markov modeling was used in the vast majority of the previous decision analytic models in the field of bariatric surgery [7, 25, 35-42].

This cost-effectiveness analysis showed, in Swedish settings, that bariatric surgery has a cost saving effect on the

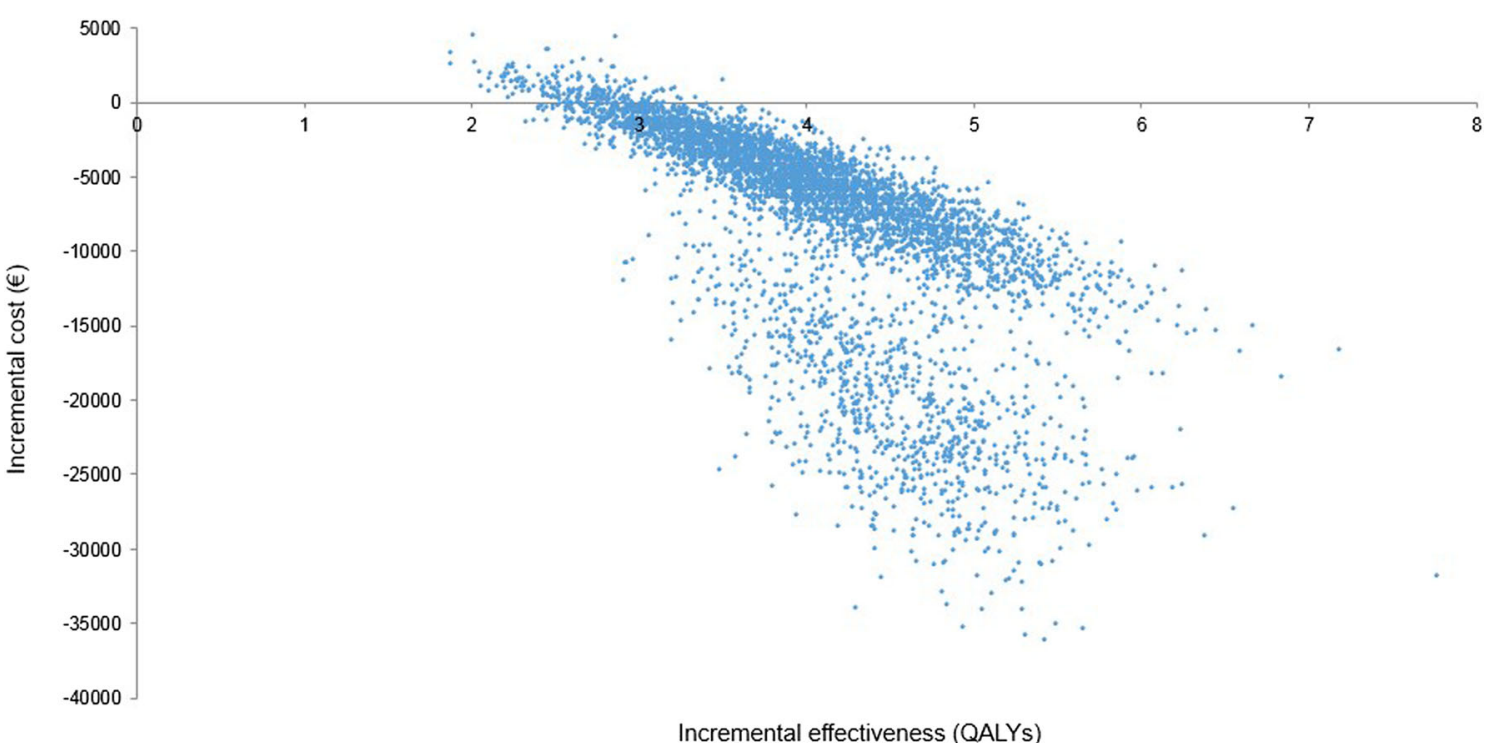

Fig. 2 Cost-effectiveness acceptability plane. The figure shows results of probabilistic sensitivity analysis at the lifetime horizon. Each dot represents results (change in cost and QALYs) for one simulated patient. The figure presents two populations which differ by the presence or absence of diabetes mellitus at the start of the model (diabetic patients have a higher level of cost saving). Analysis shows that bariatric surgery leads to additional benefits (increase in QALYs) in all patients, and cost saving (lower cost compared with continuation of optimal medical treatment) in majority of patients 
health care system over the patient's lifetime and is associated with substantial clinical benefits. If these clinical benefits are extrapolated to the entire population of Swedish patients who underwent surgery in $2012(n=7900$ from a population of around nine million people), it would result in a gain of 6320 person-years or 32,390 quality-adjusted person-years. Over the lifetime of the treated cohort, the Swedish health care system will save up to $€ 66$ million. Both amounts of cost savings and additional life years/QALYs over lifetime are provided after discounting at $3 \%$ rate annually. This is in line with standard methodology in health economics [4, 23, 31] and Swedish recommendations [27], and it is used to reflect important phenomena of patients valuing immediate benefits more, than benefits in the future. When no discounting is applied, expected benefits and cost saving are even greater (Table S14). The results of the analysis were stable in multiple sensitivity and scenario analyses including usage of very conservative estimate of the effect of surgery on BMI from recent systematic literature review and network meta-analysis [44].

In addition to the ability to save cost to the health care system over the lifetime of the patients, bariatric surgery was shown to be cost-effective already 2 years after procedure. Although decision-makers in Sweden and other European countries usually require long enough time horizon for analysis to capture all clinical and economic consequences of intervention, ability to rapidly demonstrate good value for money can support implementation of surgery among private payers/ insurers.

Our analysis is the first attempt to quantify the potential impact of extensive waiting lists on the cost and clinical outcomes of bariatric surgery in Sweden. While it indicates the importance of reducing waiting time, few studies have specifically focused on this parameter $[43,45,46]$. Results of the present study highlight the necessity to reduce waiting lists and to remove unnecessary barriers to allow a greater utilization of surgery for patients unresponsive to conventional medical management.

The analysis also showed that gastric bypass remains the most economically beneficial surgical option. Although gastric bypass is the dominant treatment option in Sweden, we have tested a number of hypothetical scenarios of reduction of use of gastric bypass and corresponding increase of use of sleeve gastrectomy and adjustable gastric banding. Reduction of proportion of gastric bypass from 98 to $60 \%$ will result in a loss of $€ 1156$ and 0.6 QALYs per patient and, for the patient population who underwent surgery in 2012, it represents loss of $€ 9.1$ million and 2844 QALYs for the lifetime of the cohort.

Our analysis is based on a comprehensive decision analytic model, which had both internal technical and external validation against three large clinical studies and the Scandinavian Obesity Surgery Registry. The present study extends the already existing body of evidence on the economic impact of surgery either derived from decision analysis modeling [7, 25, 35-40, 47-49] or real-world economic analyses [50-57]. Our results are in agreement with the overall estimates from other analyses. These studies have either shown the cost saving effect of surgery or its very high cost-effectiveness, which places bariatric surgery in a preferable position when health care priorities have to be established.

Another interesting finding of the analysis is negligible impact of increase of proportion of high-volume centers on cost of surgery over lifetime of patients (Figures S7 and S8). Although improved quality of care may have important shortterm costs and clinical outcomes, over the lifetime of the cohort, it does not play an important role, as key cost drivers are cost of long-term complications of surgery.

The study has a number of limitations. First, we acknowledge that every decision analytic model is a simplification of true health care systems and ideal source of information about cost and clinical benefits of comparative treatment strategies should be derived from randomized controlled trials (RCTs). Nevertheless, in situations where there is a lack of RCTs with appropriate comparators, duration of follow-up, and comprehensive data collection, modeling is inevitable. Second, our model does not include all potential obesity-related diseases (obstructive sleep apnea, musculoskeletal disorders, cancer, obstetrics and gynecology disorders) for which clinical evidence of the beneficial effect of bariatric surgery is emerging. The inclusion of these health states may further increase its cost benefit. Third, our model does not distinguish between the different populations of diabetic patients who may have better or worse outcomes of surgical intervention as reported in a number of recent studies [58-60]. Fourth, the current surgical and conventional management approaches may differ from those used in the studies that provided the major data inputs (i.e., SOS study). Fifth, the utilization of sleeve gastrectomy and gastric banding is very limited in Sweden. Thus, the extrapolation of our results to countries with a higher utilization of these two procedures may be limited. Sixth, data about routine pre- and post-surgery as well as routine conservative management of surgical candidates in Sweden were limited, so assumptions were required. As it was shown in the sensitivity analysis, the cost of routine post-surgery care may influence the cost-effectiveness of bariatric surgery.

In conclusion, using a comprehensive decision analytic model over the patient's lifetime, we have shown that bariatric surgery is associated with significant clinical benefits that lead to cost savings to the health care system.

Conflict of Interest Dr. Borisenko, Mr. Adam, Ms. Zhang, and Ms. Colpan are employees of Synergus AB, which received a grant from Covidien Inc., during the conduct of the study. Dr. Hedenbro reports lecturing fees from Johnson \& Johnson and lecturing fees and research funding from Covidien Inc., all outside the submitted work. Drs. FunchJensen and Ahmed have nothing to disclose. 
Statement of Human and Animal Rights This article does not contain any studies with human participants or animals performed by any of the authors.

Funding This study was supported by Covidien Inc. The sponsor had no influence or editorial control over the content of the study.

Open AccessThis article is distributed under the terms of the Creative Commons Attribution License which permits any use, distribution, and reproduction in any medium, provided the original author(s) and the source are credited.

\section{References}

1. Padwal R, Li SK, Lau DC. Long-term pharmacotherapy for obesity and overweight. Cochrane Database Syst Rev. 2004;3:CD004094. doi:10.1002/14651858.CD004094.pub2.

2. Shaw K, Gennat H, O'Rourke P, Del Mar C. Exercise for overweight or obesity. Cochrane Database Syst Rev. 2006;4:CD003817. doi:10. 1002/14651858.CD003817.pub3.

3. Shaw K, O'Rourke P, Del Mar C, Kenardy J. Psychological interventions for overweight or obesity. Cochrane Database Syst Rev. 2005;2: CD003818. doi:10.1002/14651858.CD003818.pub2.

4. Drummond MF, Sculpher M, Torrance GW, O’Brien BJ, Stoddart GL. Methods for the economic evaluation of health care programmes. Thirdth ed. Oxford: Oxford University Press; 2005.

5. D'Agostino RB, Vasan RS, Pencina MJ, Wolf PA, Cobain M, Massaro JM, et al. General cardiovascular risk profile for use in primary care: the Framingham Heart Study. Circulation. 2008;117 (6):743-53. doi:10.1161/circulationaha.107.699579.

6. Anderson KM, Odell PM, Wilson PW, Kannel WB. Cardiovascular disease risk profiles. Am Heart J. 1991;121(1 Pt 2):293-8.

7. Picot J, Jones J, Colquitt JL, Gospodarevskaya E, Loveman E, Baxter $\mathrm{L}$, et al. The clinical effectiveness and cost-effectiveness of bariatric (weight loss) surgery for obesity: a systematic review and economic evaluation. Health Technol Assess. 2009;13(41):1-190. doi:10.3310/ hta13410. 215-357, iii-iv.

8. Colditz GA, Willett WC, Rotnitzky A, Manson JE. Weight gain as a risk factor for clinical diabetes mellitus in women. Ann Intern Med. 1995;122(7):481-6.

9. Sjostrom L. Lifestyle, diabetes, and cardiovascular risk factors 10 years after bariatric surgery. N Engl J Med. 2004;351:2683-93.

10. Birkmeyer NJ, Dimick JB, Share D, Hawasli A, English WJ, Genaw J, et al. Hospital complication rates with bariatric surgery in Michigan. JAMA. 2010;304(4):435-42. doi:10.1001/jama.2010.1034.

11. Finks JF, Kole KL, Yenumula PR, English WJ, Krause KR, Carlin $\mathrm{AM}$, et al. Predicting risk for serious complications with bariatric surgery: results from the Michigan Bariatric Surgery Collaborative. Ann Surg. 2011;254(4):633-40. doi:10.1097/SLA. 0b013e318230058c.

12. Scandinavian Obesity Surgery Registry. Annual Report 2011. [cited 2014 September 20]. Available from: http://www.ucr.uu.se/soreg/ index.php/dokument/cat_view/58-dokument/57-arsrapporter.

13. Sjöström L, Peltonen $\bar{M}$, Jacobson P, Sjöström CD, Karason K, Wedel $\mathrm{H}$, et al. Bariatric surgery and long-term cardiovascular events. JAMA J Am Med Assoc. 2012;307(1):56-65. doi:10.1001/jama. 2011.1914.

14. OECD. OECD Factbook 2011: Economic, Environmental and Social Statistics 2011. [cited 2014 September 20]. Available from: http:// www.oecd-ilibrary.org/economics/oecd-factbook_18147364.
15. Henriksson F, Agardh CD, Berne C, Bolinder J, Lönnqvist F, Stenström P, et al. Direct medical costs for patients with type 2 diabetes in Sweden. J Intern Med. 2000;248(5):387-96.

16. Ghatnekar O, Persson U, Glader EL, Terént A. Cost of stroke in Sweden: an incidence estimate. Int J Technol Assess Health Care. 2004;20(3):375-80.

17. Henriksson M, Russell D, Bodegard J, Kjeldsen S, Hasvold P, Stålhammar J, et al. Health-care costs of losartan and candesartan in the primary treatment of hypertension. J Hum Hypertens. 2011;25(2):130-6. doi:10.1038/jhh.2010.36.

18. Wilhelmsen L, Welin L, Odén A, Björnberg A. Saving lives, money and resources: drug and $\mathrm{CABG} / \mathrm{PCI}$ use after myocardial infarction in a Swedish record-linkage study. Eur J Health Econ. 2010;11(2):17784. doi:10.1007/s10198-009-0161-6.

19. Agvall B, Borgquist L, Foldevi M, Dahlström U. Cost of heart failure in Swedish primary healthcare. Scand J Prim Health Care. 2005;23 (4):227-32. doi:10.1080/02813430500197647.

20. Levy E, Gabriel S, Dinet J. The comparative medical costs of atherothrombotic disease in European countries. Pharmacoeconomics. 2003;21(9):651-9.

21. Andersson F, Kartman B. The cost of angina pectoris in Sweden. Pharmacoeconomics. 1995;8(3):233-44.

22. Statistics Sweden. Consumer Price Index (CPI) 2012 [cited 2014 September 20]. Available from: http://www.scb.se/Pages/ TableAndChart_272152.aspx.

23. Gray A, Clarke P, Wolstenholme J, and Wordsworth S. Applied Methods of Cost-effectiveness Analysis in Healthcare. Oxford: Oxford University Press; 2010.

24. OECD. Purchasing Power Parities for GDP and related indicators [cited 2014 September 20]. Available from: http://stats.oecd.org/ index.aspx?DataSetCode=PPPGDP

25. Ackroyd R, Mouiel J, Chevallier JM, Daoud F. Cost-effectiveness and budget impact of obesity surgery in patients with type-2 diabetes in three European countries. Obes Surg. 2006;16(11):1488-503. doi: 10.1381/096089206778870067.

26. Sullivan PW, Slejko JF, Sculpher MJ, Ghushchyan V. Catalogue of EQ-5D scores for the United Kingdom. Med Decis Making Int J Soc Med Decis Making. 2011;31(6):800-4. doi:10.1177/ 0272989X11401031.

27. Edling A, Stenberg A. General guidelines for economic evaluations from the Pharmaceutical Benefits Board (LFNAR 2003:2). 2003.

28. Belgian Health Care Knowledge Centre. Threshold values for costeffectiveness in health care. KCE reports 100 C. 2008.

29. Persson U, Nordling S, Pettersson B. Kostnadseffektivitetsanalyser ett instrument för en långsiktigt hållbar läkemedelsmarknad? Kostnadseffektivitetsanalyser. 2009.

30. Hjalte K, Hjelmgren J, Johansson F, Persson U. Betalningsviljan för ett kvalitetsjusterat levnadsår-en pilotstudie. IHE Lund. 2005.

31. Briggs A, Sculpher M, and Claxton K. Decision Modelling for Health Economic Evaluation. Oxford: Oxford University Press; 2006.

32. National Institute for Health and Care Excellence. Guide to the methods of technology appraisal 2008.

33. Institute for Quality and Efficiency in Health Care. General Methods for the Assessment of the Relation of Benefits to Costs. Version 1.0. 2009.

34. Canadian Agency for Drugs and Technologies in Health. Guidelines for the Economic Evaluation of Health Technologies. 2006.

35. Keating CL, Dixon JB, Moodie ML. Cost-effectiveness of surgically induced weight loss for the management of type 2 diabetes: modeled lifetime analysis. Diabetes Care. 2009;32(4):567-74. doi:10.2337/ dc08-1749.

36. Wang BCM, Wong ES, Alfonso-Cristancho R, He H, Flum DR, Arterburn DE, et al. Cost-effectiveness of bariatric surgical procedures for the treatment of severe obesity. Eur J Health Econ. 2013. doi:10.1007/s10198-013-0472-5. 
37. Campbell J, McGarry LA, Shikora SA, Hale BC, Lee JT, Weinstein MC. Cost-effectiveness of laparoscopic gastric banding and bypass for morbid obesity. Am J Manage Care. 2010;1(16):e174-87.

38. Ikramuddin S, Klingman D, Swan T, Minshall ME. Costeffectiveness of Roux-en-Y gastric bypass in type 2 diabetes patients. Am J Manage Care. 2009;15(9):607-15.

39. Hoerger TJ, Zhang P, Segel JE, Kahn HS, Barker LE, Couper S. Costeffectiveness of bariatric surgery for severely obese adults with diabetes. Diabetes Care. 2010;33(9):1933-9. doi:10.2337/dc10-0554.

40. Faria GR, Preto JR, Costa-Maia J. Gastric bypass is a cost-saving procedure: results from a comprehensive Markov model. Obes Surg. 2013;23(4):460-6. doi:10.1007/s11695-012-0816-8.

41. Anselmino M, Bammer T, Fernández Cebrián JM, Daoud F, Romagnoli G, Torres A. Cost-effectiveness and budget impact of obesity surgery in patients with type 2 diabetes in three European countries(II). Obes Surg. 2009 Nov;19(11):1542-9. doi:10.1007/ s11695-009-9946-Z.

42. Lee YY, Veerman JL, Barendregt JJ. The cost-effectiveness of laparoscopic adjustable gastric banding in the morbidly obese adult population of Australia. PLoS One. 2013 May 22;8(5):e64965. doi:10. 1371/journal.pone.0064965.

43. Christou NV, Efthimiou E. Bariatric surgery waiting times in Canada. Can J Surg. 2009;52(3):229-34.

44. Padwal R, Klarenbach S, Wiebe N, Hazel M, Birch D, Karmali S, et al. Bariatric surgery: a systematic review of the clinical and economic evidence. J Gen Intern Med. 2011;26(10):1183-94. doi:10. 1007/s11606-011-1721-x.

45. Gregory DM, Temple Newhook J, Twells LK. Patients' perceptions of waiting for bariatric surgery: a qualitative study. Int J Equity Health. 2013;12(1):86. doi:10.1186/1475-9276-12-86.

46. Padwal RS, Majumdar SR, Klarenbach S, Birch DW, Karmali S, McCargar L, et al. Health status, quality of life, and satisfaction of patients awaiting multidisciplinary bariatric care. BMC Health Serv Res. 2012;12:139. doi:10.1186/1472-6963-12-139.

47. Mäklin S, Malmivaara A, Linna M, Victorzon M, Koivukangas V, Sintonen H. Cost-utility of bariatric surgery for morbid obesity in Finland. Br J Surg. 2011;98(10):1422-9. doi:10.1002/bjs.7640.

48. Pollock RF, Muduma G, Valentine WJ. Evaluating the costeffectiveness of laparoscopic adjustable gastric banding versus standard medical management in obese patients with type 2 diabetes in the UK. Diabetes Obes Metab. 2013;15:121-9.

49. Roubík L, Borovský J. Assessment of morbid obesity treatment cost efficiency in the Czech Republic. Metabolismus. 2012;15(3):201-6.

50. Nguyen NT, Slone JA, Nguyen X-MT, Hartman JS, Hoyt DB. A prospective randomized trial of laparoscopic gastric bypass versus laparoscopic adjustable gastric banding for the treatment of morbid obesity: outcomes, quality of life, and costs. Ann Surg. 2009;250(4): 631-41. doi:10.1097/SLA.0b013e3181b92480.

51. Ewing BT, Thompson MA, Wachtel MS, Frezza EE. A cost-benefit analysis of bariatric surgery on the South Plains region of Texas. Obes Surg. 2011;21(5):644-9. doi:10.1007/s11695-010-0266-0.

52. Keating CL, Peeters A, Swinburn B, Carter R, Moodie ML. Pharmaceutical utilisation and costs before and after bariatric surgery. Int J Obes. 2013;37(11):1467-72. doi:10.1038/ijo.2013.24.

53. Finkelstein EA, Allaire BT, DiBonaventura MD, Burgess SM. Direct and indirect costs and potential cost savings of laparoscopic adjustable gastric banding among obese patients with diabetes. J Occup Environ Med. 2011;53(9):1025-9. doi:10.1097/JOM. 0b013e318229aae4

54. Keating CL, Dixon JB, Moodie ML, Peeters A, Playfair J, O'Brien PE. Cost-efficacy of surgically induced weight loss for the management of type 2 diabetes: a randomized controlled trial. Diabetes Care. 2009;32(4):580-4. doi:10.2337/dc08-1748.

55. Ghiassi S, Morton J, Bellatorre N, Eisenberg D. Short-term medication cost savings for treating hypertension and diabetes after gastric bypass. Surg Obes Relat Dis. 2012;8(3):269-74. doi:10.1016/j.soard. 2011.05.009.

56. Ojo P, Valin E. Cost-effective restrictive bariatric surgery: laparoscopic vertical banded gastroplasty versus laparoscopic adjustable gastric band. Obes Surg. 2009;19(11):1536-41. doi:10.1007/ s11695-008-9771-9.

57. Neovius M, Narbro K, Keating C, Peltonen M, Sjöholm K, Agren G, et al. Health care use during 20 years following bariatric surgery. JAMA. 2012;308(11):1132-41. doi:10.1001/2012.jama.11792.

58. Ramos-Levi AM, Matia P, Cabrerizo L, Barabash A, SanchezPernaute A, Calle-Pascual AL, et al. Statistical models to predict type 2 diabetes remission after bariatric surgery. J Diabetes. 2014. doi:10. 1111/1753-0407.12127.

59. Lee YC, Lee WJ, Liew PL. Predictors of remission of type 2 diabetes mellitus in obese patients after gastrointestinal surgery. Obes Res Clin Pract. 2013;7(6):e494-500. doi:10.1016/j.orcp.2012.08.190.

60. Still CD, Wood GC, Benotti P, Petrick AT, Gabrielsen J, Strodel WE, et al. Preoperative prediction of type 2 diabetes remission after Rouxen-Y gastric bypass surgery: a retrospective cohort study. Lancet Diabetes Endocrinol. 2014;2(1):38-45. doi:10.1016/s2213-8587 (13)70070-6.

61. Husereau D, Drummond M, Petrou S, Carswell C, Moher D, Greenberg D, et al. Consolidated health economic evaluation reporting standards (CHEERS)-explanation and elaboration: a report of the ISPOR Health Economic Evaluation Publication Guidelines Good Reporting Practices Task Force. Value Health. 2013;16(2): 231-50. doi:10.1016/j.jval.2013.02.002.

62. Ikramuddin S. Roux-en-Y gastric bypass vs intensive medical management for the control of type 2 diabetes hypertension and hyperlipidemia: the Diabetes Surgery Study Randomized Clinical Trial. JAMA. 2013;309(21):2240-9.

63. Ikramuddin S, Korner J, Lee WJ, Connett JE, Inabnet WB, Billington $\mathrm{CJ}$, et al. Roux-en-Y gastric bypass vs intensive medical management for the control of type 2 diabetes, hypertension, and hyperlipidemia: the Diabetes Surgery Study Randomized Clinical Trial. JAMA. 2013;309(21):2240-9. doi:10.1001/jama.2013.5835.

64. Schauer P, Kashyap SR, Wolski K, Brethauer SA, Kirwan JP, Pothier $\mathrm{CE}$, et al. Bariatric surgery versus intensive medical therapy in obese patients with diabetes. N Engl J Med. 2012;366(17):1567-76.

65. Angrisani L, Lorenzo M, Borrelli V. Laparoscopic adjustable gastric banding versus Roux-en-Y gastric bypass: 5-year results of a prospective randomized trial. Surg Obes Relat Dis. 2007;3(2):127-32. doi:10.1016/j.soard.2006.12.005. discussion 32-3.

66. Stoeckli R, Chanda R, Langer I, Keller U. Changes of body weight and plasma ghrelin levels after gastric banding and gastric bypass. Obes Res. 2004;12(2):346-50. doi:10.1038/oby.2004.43.

67. Bessler M, Daud A, Kim T, DiGiorgi M. Prospective randomized trial of banded versus nonbanded gastric bypass for the super obese: early results. Surg Obes Relat Dis Off J Am Soc Bariatric Surg. 2007;3(4):480-4. doi:10.1016/j.soard.2007.01.010. discussion 4-5.

68. Karamanakos SN, Vagenas K, Kalfarentzos F, Alexandrides TK. Weight loss, appetite suppression, and changes in fasting and postprandial ghrelin and peptide-YY levels after Roux-en-Y gastric bypass and sleeve gastrectomy: a prospective, double blind study. Ann Surg. 2008;247(3):401-7. doi:10.1097/SLA.0b013e318156f012.

69. Dixon JB, Brien PEO, Playfair J, Chapman L, Schachter LM, Skinner S, et al. Adjustable gastric banding and conventional therapy for type 2 diabetes. JAMA. 2008;299(3):316-23.

70. van Dielen FMH, Soeters PB, de Brauw LM, Greve JWM. Laparoscopic adjustable gastric banding versus open vertical banded gastroplasty: a prospective randomized trial. Obes Surg. 2005;15(9): 1292-8. doi:10.1381/096089205774512456.

71. Mathus-Vliegen EMH, de Wit LT. Health-related quality of life after gastric banding. Br J Surg. 2007;94(4):457-65. doi:10.1002/bjs. 5607. 
72. Fried M, Hainer V, Basdevant A, Buchwald H, Deitel M, Finer N, et al. Interdisciplinary European guidelines on surgery of severe obesity. Obes Facts. 2008;1(1):52-9. doi:10.1159/000113937.

73. Sjukvårdsregionen Västra Götaland. Utomlänspriser. 2012.

74. Bolin K, Gip C, Mörk AC, Lindgren B. Diabetes, healthcare cost and loss of productivity in Sweden 1987 and 2005-a register-based approach. Diabet Med. 2009;26(9):928-34. doi:10.1111/j.14645491.2009.02786.x

75. Lindgren P, Glader EL, Jönsson B. Utility loss and indirect costs after stroke in Sweden. Eur J Cardiovasc Prev Rehabil. 2008;15(2):230-3. doi:10.1097/HJR.0b013e3282f37a22.

76. Zethraeus N, Molin T, Henriksson P, Jönsson B. Costs of coronary heart disease and stroke: the case of Sweden. J Intern Med. 1999;246 (2):151-9.

77. Dahlöf B, Sever PS, Poulter NR, Wedel H, Beevers DG, Caulfield M, et al. Prevention of cardiovascular events with an antihypertensive regimen of amlodipine adding perindopril as required versus atenolol adding bendroflumethiazide as required, in the Anglo-Scandinavian Cardiac Outcomes Trial-Blood Pressure Lowering Arm (ASCOTBPLA): a multicentre randomised controlled trial. Lancet. 2005;366 (9489):895-906. doi:10.1016/S0140-6736(05)67185-1.

78. Wing RR, Bolin P, Brancati FL, Bray GA, Clark JM, Coday M, et al. Cardiovascular effects of intensive lifestyle intervention in type 2 diabetes. N Engl J Med. 2013;369(2):145-54. doi:10.1056/ NEJMoa1212914.

79. Cushman WC, Evans GW, Byington RP, Goff DC, Grimm RH, Cutler JA, et al. Effects of intensive blood-pressure control in type 2 diabetes mellitus. N Engl J Med. 2010;362(17):1575-85. doi:10. 1056/NEJMoa1001286.

80. Wolf PA, D'Agostino RB, O'Neal MA, Sytkowski P, Kase CS, Belanger AJ, et al. Secular trends in stroke incidence and mortality. The Framingham Study. Stroke. 1992;23(11):1551-5.

81. Dennis MS, Burn JP, Sandercock PA, Bamford JM, Wade DT, Warlow CP. Long-term survival after first-ever stroke: the Oxfordshire Community Stroke Project. Stroke. 1993;24(6):796800 .

82. Witt BJ, Ballman KV, Brown RD, Meverden RA, Jacobsen SJ, Roger VL. The incidence of stroke after myocardial infarction: a meta-analysis. Am J Med. 2006;119(4):354. doi:10.1016/j.amjmed.2005.10. 058. e1-9.
83. Ovbiagele B, Diener HC, Yusuf S, Martin RH, Cotton D, Vinisko R, et al. Level of systolic blood pressure within the normal range and risk of recurrent stroke. JAMA. 2011;306(19):2137-44. doi:10.1001/ jama.2011.1650.

84. Rosengren A, Wilhelmsen L, Hagman M, Wedel H. Natural history of myocardial infarction and angina pectoris in a general population sample of middle-aged men: a 16-year follow-up of the Primary Prevention Study, Göteborg, Sweden. J Intern Med. 1998;244(6): 495-505.

85. Zanchetti A, Hansson L, Dahlöf B, Elmfeldt D, Kjeldsen S, Kolloch $\mathrm{R}$, et al. Effects of individual risk factors on the incidence of cardiovascular events in the treated hypertensive patients of the Hypertension Optimal Treatment Study. HOT study group. J Hypertens. 2001;19(6):1149-59.

86. Krumholz HM, Merrill AR, Schone EM, Schreiner GC, Chen J, Bradley EH, et al. Patterns of hospital performance in acute myocardial infarction and heart failure 30-day mortality and readmission. Circ Cardiovasc Qual Outcomes. 2009;2(5):407-13. doi:10.1161/ CIRCOUTCOMES.109.883256.

87. Arnold JM, Yusuf S, Young J, Mathew J, Johnstone D, Avezum A, et al. Prevention of heart failure in patients in the Heart Outcomes Prevention Evaluation (HOPE) study. Circulation. 2003;107(9): 1284-90.

88. Velagaleti RS, Pencina MJ, Murabito JM, Wang TJ, Parikh NI, D'Agostino RB, et al. Long-term trends in the incidence of heart failure after myocardial infarction. Circulation. 2008;118(20):205762. doi:10.1161/CIRCULATIONAHA.108.784215.

89. Poole-Wilson PA, Lubsen J, Kirwan BA, van Dalen FJ, Wagener G, Danchin N, et al. Effect of long-acting nifedipine on mortality and cardiovascular morbidity in patients with stable angina requiring treatment (ACTION trial): randomised controlled trial. Lancet. 2004;364(9437):849-57. doi:10.1016/ S0140-6736(04)16980-8.

90. Criqui MH, Langer RD, Fronek A, Feigelson HS, Klauber MR, McCann TJ, et al. Mortality over a period of 10 years in patients with peripheral arterial disease. N Engl J Med. 1992;326(6):381-6. doi: 10.1056/NEJM199202063260605.

91. Hansen LJ, Olivarius NF, Siersma V. 16-year excess all-cause mortality of newly diagnosed type 2 diabetic patients: a cohort study. BMC Public Health. 2009;9:400. doi:10.1186/1471-2458-9-400. 